\title{
Tropomyosins: Potential Biomarkers for Urothelial Bladder Cancer
}

\author{
Nada Humayun-Zakaria ${ }^{1, *(D)}$, Roland Arnold ${ }^{1}$, Anshita Goel ${ }^{1}$, Douglas Ward ${ }^{1}$, Stuart Savill ${ }^{2} \mathbb{D}$ \\ and Richard T. Bryan 1 (1) \\ 1 Institute of Cancer and Genomic Sciences, College of Medicine and Dental Sciences, University of \\ Birmingham, Birmingham B15 2TT, UK; R.Arnold.2@bham.ac.uk (R.A.); A.Goel@bham.ac.uk (A.G.); \\ D.G.WARD@bham.ac.uk (D.W.); R.T.Bryan@bham.ac.uk (R.T.B.) \\ 2 North Wales Clinical Research Centre, Betsi Cadwaladr University Health Board, Wrexham LL13 7YP, UK; \\ STUART.SAVILL@wales.nhs.uk \\ * Correspondence: n.humayun-zakaria@bham.ac.uk
}

Received: 23 January 2019; Accepted: 1 March 2019; Published: 4 March 2019

check for updates

\begin{abstract}
Despite the incidence and prevalence of urothelial bladder cancer (UBC), few advances in treatment and diagnosis have been made in recent years. In this review, we discuss potential biomarker candidates: the tropomyosin family of genes, encoded by four loci in the human genome. The expression of these genes is tissue-specific. Tropomyosins are responsible for diverse cellular roles, most notably based upon their interplay with actin to maintain cellular processes, integrity and structure. Tropomyosins exhibit a large variety of splice forms, and altered isoform expression levels have been associated with cancer, including UBC. Notably, tropomyosin isoforms are detectable in urine, offering the potential for non-invasive diagnosis and risk-stratification. This review collates the basic knowledge on tropomyosin and its isoforms, and discusses their relationships with cancer-related phenomena, most specifically in UBC.
\end{abstract}

Keywords: tropomyosin; TPM; urothelial bladder cancer; NMIBC

\section{Introduction}

Each year, circa 100,000 patients in the UK undergo investigation for haematuria, the most common symptom of urothelial bladder cancer (UBC). Around $10 \%$ of these patients are subsequently diagnosed with UBC [1], of which 75-80\% will have non-muscle-invasive disease (NMIBC: stages $\mathrm{Ta} / \mathrm{T} 1 / \mathrm{Tis})$ [2]. The remaining $20-25 \%$ of patients are diagnosed with muscle-invasive disease (MIBC: stages $\mathrm{T} 2+$ ) following transurethral resection of bladder tumour (TURBT), and undergo further staging investigations before receiving definitive treatment.

For NMIBC patients, long-term cystoscopic surveillance is the mainstay of management following initial transurethral resection (TURBT) and adjuvant intravesical therapy [3]. Cystoscopy is expensive, invasive, uncomfortable, and carries morbidity [4]. Consequently, bladder cancer is one of the most expensive malignancies to manage on a per-patient basis from diagnosis to death, the majority of which is attributable to the long-term treatment and surveillance of NMIBC [5]. Furthermore, significant patient burden and healthcare costs are incurred by the investigation of patients with haematuria, over $80 \%$ of whom are subsequently diagnosed with non-malignant conditions or no abnormality [1].

The development of accurate urinary biomarkers for the non-invasive detection of UBC could transform patient pathways by reducing reliance on cystoscopy, which is burdensome for patients and expensive for healthcare providers [6]. Hence, non-invasive diagnosis is a key unmet need for UBC [7], and has become a global research challenge. A number of commercial biomarkers exist and, to date, six have been approved by the FDA for the detection and surveillance of UBC (NMP22, NMP22 
BladderChek Test, BTA TRAK, BTA Stat, UroVysion ${ }^{\circledR}$ FISH and ImmunoCyt). However, none have been accepted into routine clinical practice due to poor performance and/or poor evidence $[3,8,9]$. Notably, patients require tests that are at least as accurate as cystoscopy [10]. However, cystoscopy itself is not infallible: sensitivity has been estimated at $85 \%$, with $87 \%$ specificity $[6,11]$ (and it is highly operator-dependent). Thus, as a viable alternative to cystoscopy for patients and healthcare providers alike, non-invasive urinary biomarkers need to match or exceed the sensitivity and specificity of conventional flexible cystoscopy, ideally with utility to also risk-stratify patients above and beyond conventional clinico-pathological tools [3]. This review focuses on the potential use of tropomyosin (TPM) in the detection and stratification of bladder cancer. TPM performs isoform-specific functions within normal cells of the urothelium, and alteration in the isoform expression and concomitant spliceform switching can be observed in the event of bladder carcinogenesis, as will be discussed later in Section 4.

\section{Tropomyosin}

\subsection{Background and Diversity}

Tropomyosin was first identified as a myofibrillar structural protein, involved in contractile function within skeletal and cardiac muscle [12]. TPM is a key regulator in the excitation-contraction coupling mechanism within muscle cells that allows synchronous movements of the myosin heads with the corresponding actin filaments. Though tropomyosins are largely seen to be part of muscle cells, their functions are not limited to muscle cells alone. TPMs have been found in all living cells, including yeast, with the exception of plants and bacteria [13]. TPMs form coiled-coil actin-binding dimers involved in the structural and functional integrity of both the thin-filaments in muscle and the actin cytoskeleton in non-muscle cells. They form an integral component in the regulation of cellular viability and differentiation, and any alterations in gene expression impact cell morphogenesis [13]. The tropomyosin genes thus influence cellular motility, cell-cell adhesion and extracellular interactions, as seen in their contribution to cancer cell metastasis via cell proliferation, migration and invasion [13]. As we see in Sections 5 and 8, isoform usage and expression levels change during carcinogenesis in tissue-specific patterns, highlighting the complexity of TPM gene and splicing regulation.

The biodiversity of the gene products is achieved by the expression of multiple isoforms and was revealed in greater detail following the publication of the complete human genome [14]. The human genome contains only four genes of the tropomyosin family, however, by the use of differential promoter sequences and splicing events, more than 40 different tropomyosin isoforms are generated from these four genes. The four loci are named $\alpha-, \beta-, \gamma$ - and $\delta$ - genes (formally known as TPM1, TPM2, TPM3 and TPM4, respectively). The gene loci are widely dispersed and are not interlinked: 15q22, 9p13, $1 \mathrm{q} 22$ and 19p13 [15]. Historically, research on the usage of tropomyosin isoforms for tissue-specific functions generated a myriad of names that were used interchangeably. To mitigate the resulting naming confusion, an agreed nomenclature has been devised and approved by the National Centre for Biotechnology Information (NCBI) to identify the particular isoform in question [16]. For instance, the TPM1 gene encodes for the Tm2 isoform, hence named as Tpm1.2. For the purpose of clarity, this article will use the approved latest version of tropomyosin nomenclature (Table 1).

TPM isoforms are commonly divided into two categories on the basis of their molecular weight: high-molecular weight (HMW) tropomyosins are 284 amino acids in length (32-40 kDa) and low-molecular weight (LMW) TPMs are 248 amino acids in length (28-33 kDa) [17]. Of the four TPM genes, three give rise to both LMW and HMW isoforms (TPM1, 3 and 4), whereas TPM2 encodes only HMW isoforms [17]. An overview of common isoforms and their molecular weight classification can be found in Table 1. All TPM genes have an initial transcriptional promoter at exon 1a. The LMW TPMs result from alternative promoter usage, with the possibility of using either exon 1a or an internal promoter found in an intron upstream of exon $1 \mathrm{~b}$ [17]. The numbering of the exons is possible because the members of the gene family share sequence similarity at the individual exon level. 
Variable expression levels of LMW isoforms result from the ability of the genes to incorporate exon 6a internal splice variants: promoters at exon 9a, 9b, 9c and 9d from TPM1; exon 9a and 9b from TPM3; and exon 9a from TPM4 [17].

Table 1. Distribution of molecular weight over well-characterized tropomyosin (TPM) isoforms and genes. HMW: high molecular weight; LMW: low molecular weight.

\begin{tabular}{ccccc}
\hline $\begin{array}{c}\text { Tropomyosin } \\
\text { Gene }\end{array}$ & $\begin{array}{c}\text { TPM Isoforms } \\
\text { Common (Old) Name }\end{array}$ & $\begin{array}{c}\text { TPM } \\
\text { Nomenclature }\end{array}$ & $\begin{array}{c}\text { Size } \\
\text { (HMW/LMW) }\end{array}$ & $\begin{array}{c}\text { Molecular Weight } \\
\text { (kDa) }\end{array}$ \\
\hline & Tm2 & Tpm 1.6 & HMW & 36 \\
TPM1 & Tm5a & Tpm 1.7 & HMW & 34 \\
& Tm5b & Tpm 1.8 & LMW & 30 \\
TPM2 & Tm6 1.9 & LMW & 30 \\
TPM3 & Tm1 & Tpm 1.4 & HMW & 40 \\
TPM4 & Tm5m 2.1 & HMW & 38 \\
& Tm4.1 & Tpm 3.1 4.1 & LMW & 30 \\
\hline
\end{tabular}

\subsection{Function}

Within non-muscle cells, actin forms an arbitrary pattern of intracellular cytoskeleton bound to structural proteins that play an important role in multiple cellular processes as well as in the maintenance of cell structure and integrity. TPMs are involved in the regulation of actin's interaction with binding proteins, as well as in the stabilization of the actin filament and its assembly kinetics [18-20]. Stable polymerized actin filaments are also referred to as stress fibres. The complexity of tropomyosin isoforms points to numerous tissue-specific and cell-specific functions. TPMs regulate actin polymerization through their protective ability, decreasing the rate by which actin is removed from the pointed end of the filament, which is prone to depolymerisation [20]. The relative binding capabilities of TPMs with actin are inversely proportional to their molecular weight. HMW isoforms have a 3-fold increased propensity to co-localize with actin filaments (as seen in skeletal and cardiac muscle) compared to LMW isoforms. Conversely, LMW TPMs are present in peripheral ruffles, stress fibres, or diffuse dot locations within the cell [18]. For example, Tpm3.1 has a strong affinity for actin that prevents Arp2/3-dependent branching and severing of stable actin polymers by proteins such as ADF/cofilin [20]. Disruption of the stress fibres can impact cell morphogenesis, motility and stability-phenomena observed in early tumourigenesis.

Conversely, cofilin in abundance may act synergistically with specific TPM isoforms and increase actin dynamics in normal and transformed cells [21]. Gelsolin is also known to compete with TPM in binding to actin through depolymerisation, severing and branching of actin filaments that can lead to formation of lamellipodia. This activity is regulated by isoform-specific TPMs that are associated with the target filament [22]. It can be deduced that TPMs limit lamellipodia formation and cellular migration/invasion. Myosin-motor activity is regulated by TPM in an isoform-specific manner. Fascin is another actin-bundling protein that works synergistically with Tpm1.7, and is found in abundance in filopodia [23]. It is feasible that the actin-filament-binding abilities of TPMs relative to their molecular weights could provide a route to the discovery of prognostic biomarkers. 


\subsection{Splice Form Variants}

Although over 40 different TPM isoforms have been identified to date, it should be borne in mind how many of these isoforms actually give rise to functional protein molecules. According to the latest gene annotation information available (Ensembl Release 94, GRCh38) supported by RNA-sequencing data, the gene products are:

1. TPM1-19 protein-coding isoforms and 6 nonsense-mediated decay (NMD) candidates

2. TPM2-8 protein-coding isoforms

3. TPM3-12 protein-coding and 2 NMD candidates

4. TPM4-14 protein-coding and 5 NMD candidates

Amongst the protein-coding isoforms, the amount of supporting evidence varies (supported by expressed sequence tags or RNA-sequencing data) and their expression is postulated to be tissue-specific [24]. In addition to the tissue-level heterogeneity of TPM isoforms, sub-cellular localization is also utilized to compartmentalize cellular roles. A large number of studies have reported mechanisms by which TPM genes generate isoform diversity [13]: for example, TPM1 codes Tpm1.6 and Tpm1.7 (Tm2 and Tm3, respectively), yet also produces differential isoforms of Tpm1.8 and Tpm1.9 (Tm5a and Tm5b) via alternative splicing events. These events are tissue-specific and have distinct functions in their destined locations [25].

\section{TPM Expression and Signalling Pathways in Cancer}

The interactions of tropomyosin isoforms with their actin-binding proteins influences the functional fate of individual cells, maintained by the signalling pathways responsible for apoptosis, and hence the regulation of cell cycle and prevention of tumour growth in vivo. Alterations of TPM expression are a key feature of the phenotypic changes of transformed cells. Oncogene-mediated alteration within signalling pathways affects TPM expression levels. Mutagenic alterations mediated by Smad and MAPK pathways play a pivotal role in development of carcinogenesis in UBC [26]. The transforming growth factor beta (TGF- $\beta$ ) family of cytokines play important roles as tumour suppressors by inducing pro-apoptotic pathways in normal epithelial cells [27]. In the early stages of tumorigenesis in most epithelial cells, alterations within TGF- $\beta$ regulation in transformed cells cause a shift towards the progression of disease, as a result of immunosuppression and pro-angiogenesis [28]. TGF- $\beta$ interacts with TPM by upregulating the expression of TPM1 and TPM2, encoding for the HMW isoforms Tpm2.1, 1.6, 1.7 and 1.4 (Tm1, 2, 3 and 6 respectively). These isoforms are necessary for the formation of stress fibres, reducing cell motility and migration. Activation of the Ras-ERK pathway inhibits the TGF- $\beta$ induction of stress fibres by suppressing the expression of tropomyosin, leading to a more motile and invasive phenotype [26]. Additional pathways identified in the propagation of UBC include members of the $\mathrm{p} 53 / \mathrm{Rb}$ and RTK/RAS/P13K pathway. Notably, genetic alterations within Notch and Hedgehog signalling pathways are responsible for tumour progression [29]. These cellular pathways either directly or indirectly inhibit TPM gene expression, thereby decreasing the formation of TPM-actin polymers, destabilizing cellular stability, and promoting motility and spread (Figure 1). 


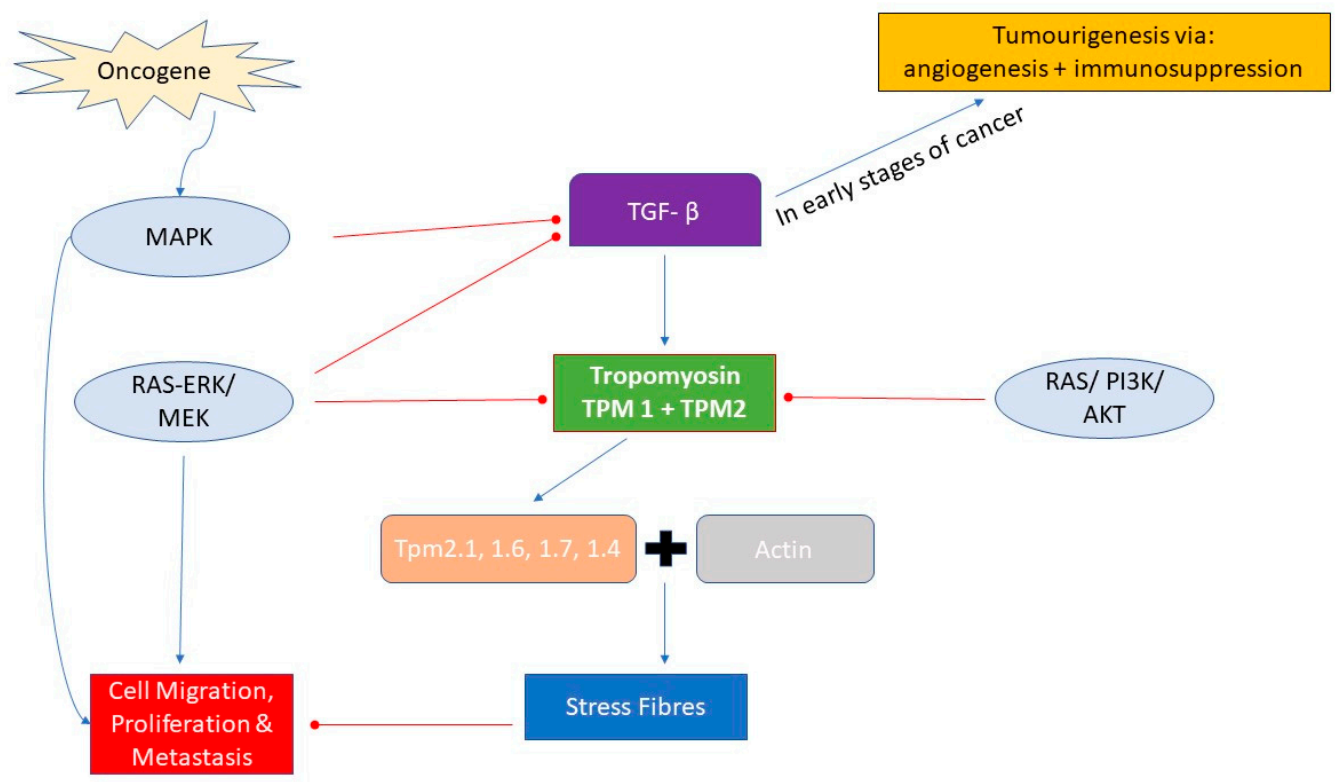

Figure 1. Cellular pathways involved in regulation of TPM binding with actin to form stress fibres to stabilize cellular structure and prevent cell motility.

\section{Tropomyosin and Urothelial Bladder Cancer}

\subsection{Potential Molecular Mechanisms of Regulation of TPM Isoform Usage}

In 2000, Hanahan and Weinberg described the six "hallmarks of cancer" that we have previously described in the context of UBC carcinogenesis [30-32]. A revised version in 2011 added two more important mechanisms-"reprogramming of energy metabolism" and "evading immune destruction" - that sustain tumour progression and disease [33]. UBC tumourigenesis is complex and multifactorial, and the specific molecular processes are beyond the scope of this review. Hence, we will focus on the contribution and effects of TPMs within these processes.

Normal urothelial cells contain an abundance of HMW TPM isoforms of the TPM1 and TPM2 genes [34]. These (Tpm1.6 and Tpm1.7) are incorporated within actin bundles to stabilize stress fibre formation, maintain cellular integrity and prevent motility [20]. In the event of DNA damage, TPM1 rescues transformed cells by acting in conjunction with long non-coding RNA MEG3 (Maternally expressed gene 3) in inhibiting cell proliferation, causing cell cycle arrest in stage G0/G1 (with dampening of $\mathrm{G} 2 / \mathrm{M}$ ), and promoting apoptosis (with upregulation of Bcl2-associated X (BaX) and caspase-3, and downregulation of Bcl2 and cyclin D1) [35].

Cell-cell adhesion is maintained and monitored in the epithelial zonula adherens. Cell adhesion and cytokinesis are established by Tpm2.1, and are involved in the process of anoikis (a form of cell death induced by detachment from the extracellular matrix) [20]. Tpm2.1 expression is similar in both NMIBC and MIBC. It has been hypothesised that the expression of TPM2 is an early event during bladder carcinogenesis [34,36]: in the initiation phase of tumorigenesis in UBC, HMW isoforms Tpm1.6 and Tpm2.1 have markedly reduced expression levels [34]. With ongoing transformation incited by either oncogenes, carcinogens, oncogenic DNA and/or RNA viruses, immunity to antigrowth signals is achieved. A notable association exists between TPM1, miR-96 (microRNA 96), and the long non-coding RNA MEG3 (Maternally expressed gene 3), where MEG3 and TPM1 are downregulated and miR-96 levels are upregulated. Regulation of isoform-specific expression by micro-RNA is generated by targeting the FOXQ1 gene, which induces epithelial-mesenchymal transition (EMT, the process by which the epithelial cells acquire characteristics of mesenchymal cells), promoting the progression of disease [35]. Suppression of TPM1 is a hallmark of EMT: loss of polarity and disassembly of cell junctions as a precursor to invasion and metastasis. 
In UBC, the MAPK pathway promotes limitless replicative capability, resulting in uncontrolled cellular proliferation, growth and invasion [31]. MAPK activation induces TPM isoform switching due to alternative promotor usage and maintains the ability of transformed cells to express high levels of Tpm3.1 [35]. Tpm3.1 is an important TPM isoform associated with multiple cancers, including UBC, and is involved in a multitude of cellular processes. Tpm3.1 regulates the uptake of glucose within the adipose cells via the insulin-stimulated GLUT4 transporter in the plasma membrane [37], generation of stress fibres, excitation-contraction coupling, and MEK/ERK-mediated regulation of cell proliferation [20]. Tpm3.1 also results in the failure of Myolb (unconventional myosin $\mathrm{Ib}$, a key intracellular organelle transporter) to not recognize actin filaments, destabilizing the cell's structural integrity [38]. Furthermore, degradation of matrix and invasion into the extracellular matrix (ECM) is propagated by the formation of lamellipodia, resulting from the overexpression of LMW isoforms [35,39]. These transformed cells eventually invade and escape from the ECM to metastasize to distant sites. Through the ectopic expression of isoforms Tpm1.6 and Tpm2.1 in cancerous cells, sustainability is maintained in a simulated normal-like morphology, which inhibits anchorage-independent growth (Table 2) [34].

As outlined above, in conjunction with other members of the cytoskeletal machinery, TPMs can mediate differential and alternative cellular capabilities for malignant transformation and invasion into (and escape from) the ECM. Furthermore, due to their many isoforms and tissue- and compartment-specific regulation, TPMs have the potential to support malignant transformation simply by aberrant regulation. This aberrant regulation may be mediated through alternative transcription factor binding site usage, as indicated by the aforementioned work in a non-cancerous cell-line by Savill et al. [17].

Table 2. TPM isoform usage in urothelial bladder carcinogenesis. EMT: epithelial-mesenchymal transition.

\begin{tabular}{|c|c|c|c|}
\hline Bladder Cancer Stage & Hallmark & Process & TPM Involvement \\
\hline Normal & $\begin{array}{l}\text { Self-sufficiency in } \\
\text { growth signals }\end{array}$ & $\begin{array}{l}\text { Normal expression levels of } \\
\text { TPM genes }\end{array}$ & $\begin{array}{l}\text { Tpm } 1.6 \text { and Tpm } \\
\text { 1.7-formation of stress fibres, } \\
\text { cell stability, reduced motility }\end{array}$ \\
\hline Suppression & $\begin{array}{l}\text { Insensitivity to growth } \\
\text { inhibitory signals }\end{array}$ & $\begin{array}{l}\text { Cell-cycle arrest in G0/G1 if } \\
\text { proliferating too much } \\
\text { TPM1 + MEG3 causes apoptosis } \\
\text { by upregulation of Bcl } 2 \text { and } \\
\text { caspase } 3\end{array}$ & $\begin{array}{l}\text { TPM1-acts as tumour } \\
\text { suppressor }\end{array}$ \\
\hline Initiation & $\begin{array}{l}\text { Evasion of programmed } \\
\text { cell death }\end{array}$ & $\begin{array}{l}\text { Decreased expression of TPM1 } \\
\text { and TPM2 } \\
\text { TPM1 is downregulated due to } \\
\text { increased micro-RNA } 96 \\
\text { (suppression lost) }\end{array}$ & $\begin{array}{l}\text { Loss of TPM1-EMT } \\
\text { Tpm } 2.1-\text { responsible for } \\
\text { anoikis, maintains cell-cell } \\
\text { adhesion }\end{array}$ \\
\hline Non-invasive & $\begin{array}{l}\text { Limitless replicative } \\
\text { potential }\end{array}$ & $\begin{array}{l}\text { Mutagenic MAPK signalling } \\
\text { activated }\end{array}$ & $\begin{array}{l}\text { Tpm3.1-cellular growth, } \\
\text { proliferation and motility }\end{array}$ \\
\hline Invasive & Sustained angiogenesis & $\begin{array}{l}\text { Invasion into extracellular } \\
\text { matrix (ECM) } \\
\text { Angiogenesis stimulated by } \\
\text { concurrent pathways }\end{array}$ & $\begin{array}{l}\text { LMW TPMs_-formation of } \\
\text { lamellipodia, increased cell } \\
\text { motility and morphogenesis }\end{array}$ \\
\hline \multirow[t]{2}{*}{ Metastasis } & $\begin{array}{l}\text { Tissue invasion and } \\
\text { death }\end{array}$ & $\begin{array}{l}\text { Breakthrough ECM with distant } \\
\text { spread }\end{array}$ & $\begin{array}{l}\text { LMW isoforms of TPM3 and } \\
\text { TPM4-Cancer cell survival, } \\
\text { focal adhesion, } \\
\text { MEK/ERK-mediated } \\
\text { proliferation }\end{array}$ \\
\hline & $\begin{array}{l}\text { Evading immune } \\
\text { destruction }\end{array}$ & $\begin{array}{l}\text { Ectopic expression of TPM1 and } \\
\text { TPM2 } \\
\text { Continued uninhibited } \\
\text { anchorage-independent growth }\end{array}$ & \\
\hline
\end{tabular}

\subsection{Isoform Switching Due to Alternative Promoter Usage}

Using the UCSC Genome Browser and the ENCODE regulatory tracks (histone marks and transcription factor binding sites), we performed an initial assessment of potential mechanisms for 
tropomyosin dysregulation by alternative transcriptional activation. These data are preliminary, since the underlying datasets are incomplete (the cell lines, the epigenetic marks, and transcription factors available have been chosen by the ENCODE consortium selectively, and do not represent all cell and tissue types). Thus, our observations should be evaluated further in the context of the cell-line and tissue type, and ultimately integrated with data from UBC. However, with these caveats, an initial inspection of the TPM gene family isoforms results in the following observations:

- TPM1 has differential presence of RXRA (retinoid $X$ receptor alpha) transcription factor binding-site (TFBS) for its LMW isoforms, as observed in two cell lines: H1-hESC (a human embryonic stem cell line) and HepG2 (a human liver cancer cell line).

- $\quad$ TPM3 and TPM4 have differential presence of the E2F1 TFBS for its LMW isoforms, as observed in the HeLa (cervical cancer) and MCF-7 (a breast cancer cell line) cell lines.

RXRA has been implicated in UBC [40] and E2F1 has been reported as an independent risk factor for UBC prognosis [41]. Given the differential presence of established cancer-related TFBS in alternative TPM promoters, and previous observations in different cancer settings, expression differences in TPM genes should be studied at the isoform level.

\section{TPM as a Marker for Cancer Prognosis}

\section{1. $U B C$}

HMW isoforms of TPMs bind tightly to actin polymers, stabilizing cellular structure and building a network of stress fibres to facilitate anchorage-dependent growth. The reduction of these isoforms and replacement by LMW isoforms-as evidenced in some malignant cells-promotes cell mobility and metastatic spread. Given their functional implications in cancer and cancer progression, TPMs-and especially TPM isoform expression-may serve as future biomarkers for disease state and prognosis. For example, decreased TPM1 expression is seen more often in high-grade urothelial carcinoma, MIBC and metastatic bladder cancer than in low-grade urothelial carcinoma, NMIBC and non-metastatic bladder cancer [35]. Low expression of TPM1 is related to worse grade and stage, as well as metastasis [35].

\subsection{Other Cancers}

Elevated levels of TPM3 expression have been found related to very poor prognosis in glioma [42]. In hepatocellular carcinoma (HCC) cell lines, amplification of TPM3 leads to upregulation of Snail-mediated EMT and downregulation of E-cadherin which is ultimately responsible for the migration and invasion of HCC and worse prognosis [43]. In other forms of urinary cancer, viz. renal cell carcinoma, diminished levels of TPM1 have been found to have strong prognostic associations-deemed a tumour-suppressor gene in this solid tumour, its association with tumour size, Fuhrman grade and smoking status has been well established, with an inversely proportional relationship between TPM1 expression and prognosis [44].

\section{Tropomyosins as Gene Fusion Partners}

Gene fusion events constitute a class of transcriptional events in which one part of a gene is fused to a fragment of another, and are observed in many different cancer types [45]. Such fusion events may be mediated by chromosomal translocations, or may be created at the transcriptomic level by potential trans-splicing [46] or transcriptional read-through [47]. Although many such fusions may be passenger events, several fusion events have been found to be recurring driving events in cancer. A prominent example is the EWS-FLI1 fusion in Ewing sarcoma, which is identified in more than $90 \%$ of cases and acts as a tumour-inducing aberrant transcription factor [48]. For TPM3 and TPM4, recurrent fusion events have been found in a variety of cancers. One of the most frequently-occurring TPM fusion events is fusion to the ALK (anaplastic lymphoma kinase) gene $[47,49,50]$. ALK itself 
is a promiscuous fusion partner. Although this tyrosine kinase appears to have its normal activity in neuronal development, it may hijack $5^{\prime}$ elements from other genes such as TPM3, allowing for altered (activated) expression and the ability to self-associate, leading to a consecutive activated kinase domain from the $3^{\prime}$ end of ALK (reviewed in [47]). TPM3 and TPM4 have been found to be frequently fused to ALK fusions (with 25 (TPM3) and 6 (TPM4) instances, respectively, listed in the curated set of fusions in the COSMIC database [51]). In a study of kinase fusion events in the TCGA cohort, Stransky et al. [50] also detected one TPM1-ALK fusion event in the 250 bladder cancer samples investigated. Another tyrosine kinase found fused with TPM3 is ROS1 (proto-oncogene tyrosine-protein kinase), found in lung cancer [52] and spitzoid melanomas [53], resulting in a similar change of kinase function as for ALK. NTRK1 (neurotrophic receptor tyrosine kinase 1) also fuses to TPM3; seen in more than $5 \%$ of thyroid cancers, the event again connects the TPM3 $5^{\prime}$ end with the NTRK1 kinase domain. In summary, TPMs can be used by kinases as fusion partners to result in high levels of expression. Future studies would be necessary to determine if they also interfere with the normal function of the TPM genes and the associated cellular processes.

\section{Detection in Urine}

Due to the evidence that TPM isoforms may be prognostic, they might also serve as biomarkers for disease and disease state. In UBC, it would be especially interesting to investigate if a urinary diagnostic test based on tropomyosins and their isoforms could be feasible. Such a test could be based on the quantification of relative isoform usage, which might be more robust against dilution and admixture of other protein/RNA species. Furthermore, due to their abundance within skeletal and cardiac muscle as noted earlier, it could be hypothesized that the secretion or release of TPM isoforms within urinary exosomes could be indicative of breach of the basement membrane and invasion into and beyond the muscular layer of the bladder wall. Note that microRNA-96 has been reported as a potential biomarker, detectable in urine [54], which might be a proxy to TPM isoform usage. In the deep RNA sequencing study of Sin et al. [55], comparing healthy and bladder cancer patients by differential gene expression in order to detect biomarkers, tropomyosins were not reported to be significantly differentially expressed between the healthy and the disease state. However, this simply indicates that the total TPM level stayed similar (differential isoform usage was not investigated). Zhao et al. created a comprehensive catalogue of proteins detectable by different proteomic approaches from the pooled urine of 24 healthy volunteers, and detected TPM1, TPM2 and TPM4 [56]. In the same work, the authors also compiled a database including five recent comprehensive proteomic studies of urine, in which TPM3 was detected twice, and TPM1 and TPM4 once (excluding their own studies and vesicle-based studies). Existing evidence shows that TPMs can be detected by mass spectrometry in urine, but does not provide information on splice form variants, and thus this aspect of biomarker utility remains uninvestigated.

In addition, RNA sequencing and proteomic research has also been conducted on urinary exosomes. Using Vesiclepedia [57], we evaluated whether TPMs are, in principle, detectable in urine samples in such experiments. We found TPM1 and TPM3 in two experiments and TPM4 in three out of a total 76 human urine experiments, all detected by mass spectrometry. This indicates some recurrence of TPMs in urinary exosomes. It also illustrates regular inclusion of TPMs in the exosomes in contrast to most detected genes, which occurred in only one study and might therefore represent a one-off occurrence.

Aside from urine, the frequency of TPMs is much higher and detectable in cell exosomes and other biofluids (Figure 2). We conducted the same analysis for microRNA-96 (using the section of Vesiclepedia for microRNA-targeted experiments) and found hsa_mir96-5p to be more specific to urine, where it is observed frequently ( 5 out of 7 experiments). Even though not all the experiments which report either TPMs or mir96 are in a UBC setting (only one experiment in UBC urine is reported in Vesiclepedia), the reported evidence indicates, in principle, the detectability in urinary exosomes by mass spectrometry and microRNA sequencing, respectively. The shortcomings encountered with 
shotgun proteomics may be mitigated in the future by using affinity-capture to enrich for TPMs, the development of specific bioinformatics approaches to identify specific isoforms and ultimately the use of targeted mass spectrometry (MRM: multiple reaction monitoring) for isoform-specific peptides.

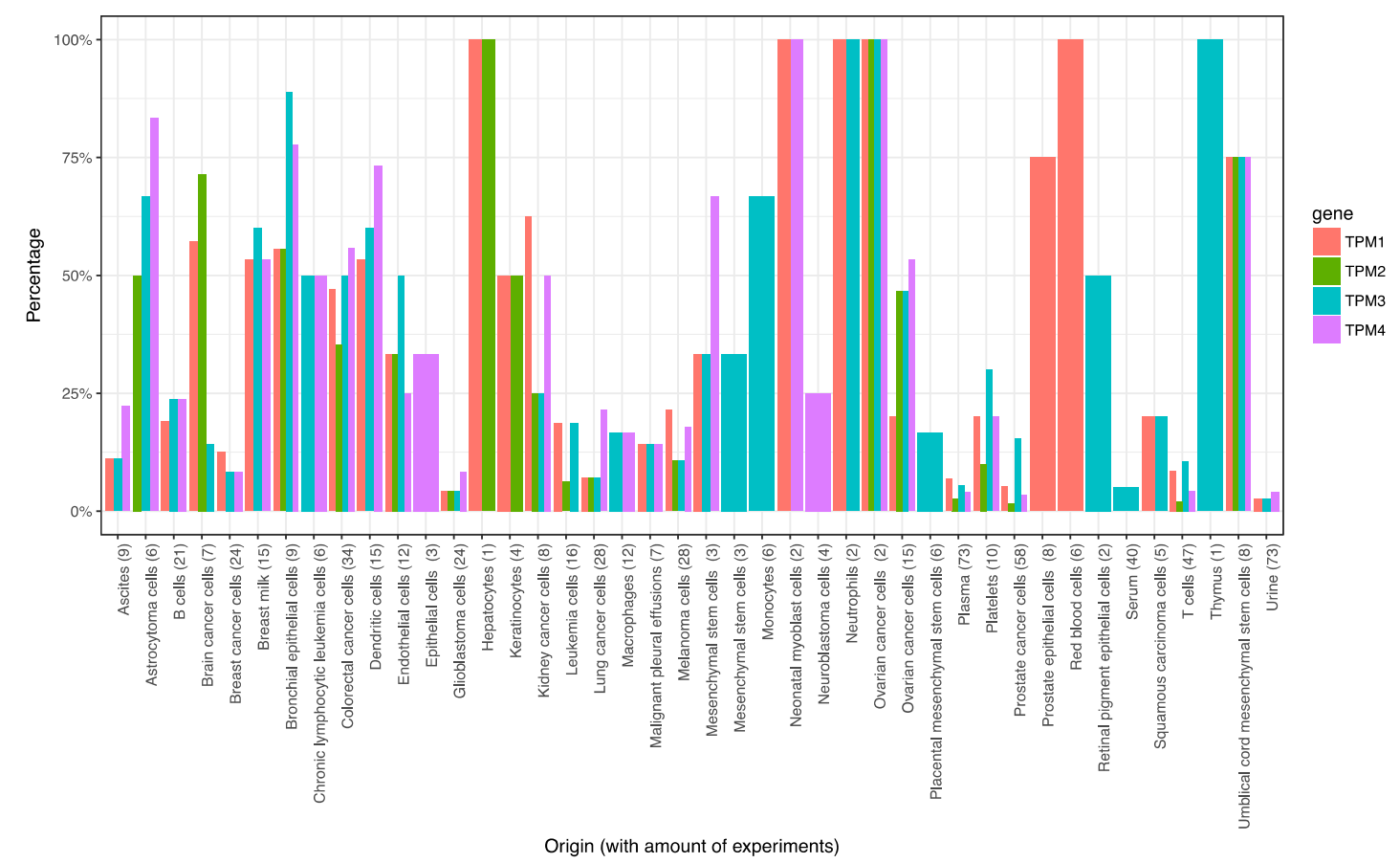

Figure 2. Frequency of TPM1, 2, 3 and 4 in experiments reported in Vesiclepedia. $X$-axis: targeted substrate/origin of the study including the amount of experiments in brackets; $Y$-axis: frequency in experiments (human-based data only, substrates with no TPM detected not shown).

\section{Tropomyosin Isoforms in Other Cancers}

Although this review focuses on TPM in UBC, we also report findings from other cancers, highlighting the general importance of tropomyosins in cancer.

\subsection{Malignant Breast Epithelial Cells}

HMW tropomyosin isoforms of TPM1 and TPM2 are expressed in normal breast epithelial cells along with the expression of LMW isoforms of TPM1 and TPM4. It has been observed that the expression of these genes is downregulated in some (although not all) malignant breast cells. An additional four novel isoforms of the TPM1 gene (that encode TPM isoforms) have been identified in nine malignant breast epithelial cell lines and are not otherwise expressed in normal adult breast tissue [58]. The TPM2 isoform has been found markedly upregulated in aggressive forms of breast cancer with lymph node metastases [58,59], and could potentially serve as a prognostic biomarker.

\subsection{Cholangiocarcinoma}

It has been demonstrated that levels of TPM1 are downregulated in intrahepatic cholangiocarcinoma and upregulated in extrahepatic cholangiocarcinoma. TPM1 regulation in this case is regulated by two important cellular pathways (i.e., RAS/PI3K/AKT and RAS/MEK/ERK), and via inhibition of epigenetic mechanisms [60]. These pathways also seem to overlap with UBC and could be targets for future therapies.

\subsection{Prostate Cancer}

Alternative splicing events give rise to several isoforms in normal cells and may not be directly involved in carcinogenesis. However, some isoforms do stimulate cellular expansion and the growth 
of malignant cells, providing a "tumour microenvironment". This phenomenon is observed in prostate cancer where mutagenic pathways cause overexpression of the TPM1 isoform, providing a platform for distant metastases [61].

\subsection{Colon Cancer}

The T84 Colon cancer cell line has been used to isolate a novel isoform of Tpm3.12, named TC22, which has been associated with colonic carcinogenesis. Its presence in benign polyps and increased expression levels by up to $75 \%$ in adenomatous dysplastic cells demonstrates a relationship with colon cancer [62].

\subsection{Oesophageal Cancer}

Ras effector regulatory pathways MEK/ERK and PI3K/AKT are compromised in oesophageal squamous cell carcinoma cell lines, leading to downregulation and decreased expression of TPM1 and TPM2 [63]. A similar pattern is observed in UBC, where downregulation of HMW TPM isoforms leads to higher grade and stage and poorer prognosis [35].

\section{Discussion and Conclusions}

Whilst tropomyosin isoforms have been investigated for decades, their true potential as cancer biomarkers has not been evaluated to date. Given their complexity of isoforms, as well as tissueand cell-specific functions, many findings remain to be discovered. They play an integral role in combination with the actin cytoskeleton in the maintenance of cell morphology, and alterations in gene expression may mediate EMT, leading to more aggressive disease and worse survival. With ongoing technological advances, we suggest that the investigation of tropomyosin isoforms could mediate further advances in UBC diagnosis and risk stratification. With the limited knowledge currently available, the detection of novel isoforms remains a challenge. Whether tropomyosin isoforms could be quantified as protein molecules within urine or genetic alterations within alternative splicing events of TPM mRNA remains to be uncovered. However, with the availability of genomic data and experimental validation, we are currently investigating the precise role of this enigmatic protein in the pathogenesis of UBC.

Funding: N Humayun-Zakaria's research is funded by QEHB Charities.

Acknowledgments: R.T. Bryan has contributed to advisory boards for Olympus Medical Systems with regards to narrow band imaging cystoscopy.

Conflicts of Interest: The authors declare no conflict of interest.

\section{Abbreviations}

$\begin{array}{ll}\text { UBC } & \text { Urothelial Bladder Cancer } \\ \text { NMIBC } & \text { Non-Muscle Invasive Bladder Cancer } \\ \text { MIBC } & \text { Muscle Invasive Bladder Cancer } \\ \text { TURBT } & \text { Transurethral Resection of Bladder Tumour } \\ \text { TPM } & \text { Tropomyosin (protein) } \\ \text { TPM } & \text { Tropomyosin gene } \\ \text { MAPK } & \text { Mitogen Activated Protein Kinase }\end{array}$

\section{References}

1. Edwards, T.; Dickinson, A.; Natale, S.; Gosling, J.; McGrath, J. A prospective analysis of the diagnostic yield resulting from the attendance of 4020 patients at a protocol-driven haematuria clinic. BJU Int. 2006, 97, 301-305. [CrossRef] [PubMed] 
2. $\quad$ Bryan, R.; Zeegers, M.; van Roekel, E.; Bird, D.; Grant, M.; Dunn, J.; Bathers, S.; Iqbal, G.; Khan, H.; Collins, S.; et al. A comparison of patient and tumour characteristics in two UK bladder cancer cohorts separated by 20 years. BJU Int. 2013, 112, 169-175. [CrossRef] [PubMed]

3. Babjuk, M.; Böhle, A.; Burger, M.; Capoun, O.; Cohen, D.; Compérat, E.; Hernández, V.; Kaasinen, E.; Palou, J.; Rouprêt, M.; et al. EAU Guidelines on Non-Muscle-invasive Urothelial Carcinoma of the Bladder: Update 2016. Eur. Urol. 2017, 71, 447-461. [CrossRef] [PubMed]

4. Mowatt, G.; Zhu, S.; Kilonzo, M.; Boachie, C.; Fraser, C.; Griffiths, T.; N’Dow, J.; Nabi, G.; Cook, J.; Vale, L. Systematic review of the clinical effectiveness and cost-effectiveness of photodynamic diagnosis and urine biomarkers (FISH, ImmunoCyt, NMP22) and cytology for the detection and follow-up of bladder cancer. Health Technol. Assess. 2010, 14. [CrossRef] [PubMed]

5. Bryan, R.; Kirby, R.; O’Brien, T.; Mostafid, H. So Much Cost, Such Little Progress. Eur. Urol. 2014, 66, $263-264$. [CrossRef] [PubMed]

6. Svatek, R.; Hollenbeck, B.; Holmäng, S.; Lee, R.; Kim, S.; Stenzl, A.; Lotan, Y. The Economics of Bladder Cancer: Costs and Considerations of Caring for This Disease. Eur. Urol. 2014, 66, 253-262. [CrossRef] [PubMed]

7. Campi, R.; Seisen, T.; Roupret, M. Unmet Clinical Needs and Future Perspectives in Non-muscle-invasive Bladder Cancer. Eur. Urol. Focus 2018, 4, 472-480. [CrossRef] [PubMed]

8. Schmitz-Dräger, B.; Droller, M.; Lokeshwar, V.; Lotan, Y.; Hudson, M.; van Rhijn, B.; Marberger, M.; Fradet, Y.; Hemstreet, G.; Malmstrom, P.; et al. Molecular Markers for Bladder Cancer Screening, Early Diagnosis, and Surveillance: The WHO/ICUD Consensus. Urol. Int. 2015, 94, 1-24. [CrossRef] [PubMed]

9. Soria, F.; Droller, M.; Lotan, Y.; Gontero, P.; D’Andrea, D.; Gust, K.; Rouprêt, M.; Babjuk, M.; Palou, J.; Shariat, S. An up-to-date catalog of available urinary biomarkers for the surveillance of non-muscle invasive bladder cancer. World J. Urol. 2018, 36, 1981-1995. [CrossRef] [PubMed]

10. Yossepowitch, O.; Herr, H.; Donat, S. Use of Urinary Biomarkers for Bladder Cancer Surveillance: Patient Perspectives. J. Urol. 2007, 177, 1277-1282. [CrossRef] [PubMed]

11. Zheng, C.; Lv, Y.; Zhong, Q.; Wang, R.; Jiang, Q. Narrow band imaging diagnosis of bladder cancer: systematic review and meta-analysis. BJU Int. 2012, 110, E680-E687. [CrossRef] [PubMed]

12. Bailey, K. Tropomyosin: A new asymmetric protein component of the muscle fibril. Biochemistry 1948, 43, 271-279. [CrossRef]

13. Gunning, P.; O'neill, G.; Hardeman, E. Tropomyosin-Based Regulation of the Actin Cytoskeleton in Time and Space. Phys. Rev. 2008, 88, 1-35. [CrossRef] [PubMed]

14. Lander, E.S.; Linton, L.M.; Birren, B.; Nusbaum, C.; Zody, M.C.; Baldwin, J.; Devon, K.; Dewar, K.; Doyle, M.; FitzHugh, W.; Funke, R.; Gage, D.; et al. Initial sequencing and analysis of the human genome. Nature 2001, 409, 860-921. [CrossRef] [PubMed]

15. Lees, J.; Bach, C.; O'Neill, G. Interior decoration: Tropomyosin in actin dynamics and cell migration. Cell Adh. Migr. 2011, 5, 181-186. [CrossRef] [PubMed]

16. Geeves, M.A.; Hitchcock-DeGregori, S.E.; Gunning, P.W. A systematic nomenclature for mammalian tropomyosin isoforms. J. Muscle Res. Cell Motil. 2014, 36, 147-153. [CrossRef] [PubMed]

17. Savill, S.; Leitch, H.F.; Harvey, J.N.; Thomas, T.H. Functional structure of the promoter regions for the predominant low molecular weight isoforms of tropomyosin in human kidney cells. J. Cell. Biochem. 2012, 113, 3576-3586. [CrossRef] [PubMed]

18. Lin, J.J.; Hegmann, T.E.; Lin, J.L. Differential localization of tropomyosin isoforms in cultured nonmuscle cells. J. Cell Biol. 1988, 107, 563-572. [CrossRef] [PubMed]

19. Janco, M.; Bonello, T.T.; Byun, A.; Coster, A.C.; Lebhar, H.; Dedova, I.; Gunning, P.W.; Böcking, T. The impact of tropomyosins on actin filament assembly is isoform specific. BioArchitecture 2016, 6, 61-75. [CrossRef] [PubMed]

20. Gunning, P.W.; Hardeman, E.C.; Lappalainen, P.; Mulvihill, D.P. Tropomyosin - master regulator of actin filament function in the cytoskeleton. J. Cell Sci. 2015, 128, 2965-2974. [CrossRef] [PubMed]

21. Kuhn, T.B.; Bamburg, J.R. Tropomyosin and ADF/Cofilin as Collaborators and Competitors. In Tropomyosin. Advances in Experimental Medicine and Biology; Gunning, P.W., Ed.; Springer: New York, NY, USA, 2008; Volume 644, pp. 232-249.

22. Ishikawa, R.; Yamashiro, S.; Matsumura, F. Differential Modulation of Actin-severing Activity of Gelsolin by Multiple Isoforms of Cultured Rat Cell Tropomyosin. J. Biol. Chem. 1989, 264, 7490-7497. [PubMed] 
23. Creed, S.J.; Desouza, M.; Bamburg, J.R.; Gunning, P.; Stehn, J. Tropomyosin isoform 3 promotes the formation of filopodia by regulating the recruitment of actin-binding proteins to actin filaments. Exp. Cell Res. 2011, 317, 249-261. [CrossRef] [PubMed]

24. Schevzov, G.; Vrhovski, B.; Bryce, N.S.; Elmir, S.; Qiu, M.R.; O’Neill, G.M.; Yang, N.; Verrills, N.M.; Kavallaris, M.; Gunning, P.W. Tissue-specific tropomyosin isoform composition. J. Histochem. Cytochem. 2005, 53, 557-570. [CrossRef] [PubMed]

25. Novy, R.E.; Lin, J.L.; Lin, C.S.; Lin, J.J. Human fibroblast tropomyosin isoforms: Characterization of cDNA clones and analysis of tropomyosin isoform expression in human tissues and in normal and transformed cells. Cell Motil. Cytoskeleton 1993, 25, 267-281. [CrossRef] [PubMed]

26. Bakin, A.; Safina, A.; Rinehart, C.; Daroqui, C.; Darbary, H.; Helfman, D. A Critical Role of Tropomyosins in TGF- $\beta$ Regulation of the Actin Cytoskeleton and Cell Motility in Epithelial Cells. Mol. Biol. Cell 2004, 15, 4682-4694. [CrossRef] [PubMed]

27. Fabregat, I.; Fernando, J.; Mainez, J.; Sancho, P. TGF-beta Signaling in Cancer Treatment. Curr. Pharm. Des. 2014, 20, 2934-2947. [CrossRef] [PubMed]

28. Roberts, A.; Wakefield, L. The two faces of transforming growth factor in carcinogenesis. Proc. Natl. Acad. Sci. USA 2003, 100, 8621-8623. [CrossRef] [PubMed]

29. Hedegaard, J.; Lamy, P.; Nordentoft, I.; Algaba, F.; Høyer, S.; Ulhøi, B.P.; Vang, S.; Reinert, T.; Hermann, G.G.; Mogensen, K.; et al. Comprehensive transcriptional analysis of early-stage urothelial carcinoma. Cancer Cell 2016, 30, 27-42. [CrossRef] [PubMed]

30. Hanahan, D.; Weinberg, R. The Hallmarks of Cancer. Cell 2000, 100, 57-70. [CrossRef]

31. Bryan, R.; Hussain, S.; James, N.; Jankowski, J.; Wallace, D. Molecular pathways in bladder cancer: Part 1. BJU Int. 2005, 95, 485-490. [CrossRef] [PubMed]

32. Bryan, R.; Hussain, S.; James, N.; Jankowski, J.; Wallace, D. Molecular pathways in bladder cancer: Part 2. BJU Int. 2005, 95, 491-496. [CrossRef] [PubMed]

33. Hanahan, D.; Weinberg, R. Hallmarks of Cancer: The Next Generation. Cell 2011, 144, 646-674. [CrossRef] [PubMed]

34. Pawlak, G.; McGarvey, T.W.; Nguyen, T.B.; Tomaszewski, J.E.; Puthiyaveettil, R.; Malkowicz, S.B.; Helfman, D.M. Alterations in tropomyosin isoform expression in human transitional cell carcinoma of the urinary bladder. Int. J. Cancer 2004, 110, 368-373. [CrossRef] [PubMed]

35. Liu, G.; Zhao, X.; Zhou, J.; Cheng, X.; Ye, Z.; Ji, Z. Long non-coding RNA MEG3 suppresses the development of bladder urothelial carcinoma by regulating miR-96 and TPM1. Cancer Biol. Ther. 2018, 19, 1039-1056. [CrossRef] [PubMed]

36. Chen, R.; Feng, C.; Xu, Y. Cyclin-dependent kinase-associated protein Cks2 is associated with bladder cancer progression. J. Int. Med. Res. 2011, 39, 533-540. [CrossRef] [PubMed]

37. Kee, A.J.; Yang, L.; Lucas, C.A.; Greenberg, M.J.; Martel, N.; Leong, G.M.; Hughes, W.E.; Cooney, G.J.; James, D.E.; Ostap, E.M.; et al. An actin filament population defined by the tropomyosin Tpm3.1 regulates glucose uptake. Traffic 2015, 16, 691-711. [CrossRef] [PubMed]

38. Bryce, N.S.; Schevzov, G.; Ferguson, V.; Percival, J.M.; Lin, J.J.; Matsumura, F.; Bamburg, J.R.; Jeffrey, P.L.; Hardeman, E.C.; Gunning, P.; et al. Specification of actin filament function and molecular composition by tropomyosin isoforms. Mol. Biol. Cell 2003, 14, 1002-1016. [CrossRef] [PubMed]

39. Brayford, S.; Bryce, N.; Schevzov, G.; Haynes, E.; Bear, J.; Hardeman, E.; Gunning, P. Tropomyosin Promotes Lamellipodial Persistence by Collaborating with Arp2/3 at the Leading Edge. Curr. Biol. 2016, 26, 1312-1318. [CrossRef] [PubMed]

40. Lerner, S.P.; McConkey, D.J.; Hoadley, K.A.; Chan, K.S.; Kim, W.Y.; Radvanyi, F.; Höglund, M.; Real, F.X. Bladder Cancer Molecular Taxonomy: Summary from a consensus meeting. Bladder Cancer 2016, 2, 37-47. [CrossRef] [PubMed]

41. Lee, J.S.; Leem, S.H.; Lee, S.Y.; Kim, S.C.; Park, E.S.; Kim, S.B.; Kim, S.K.; Kim, Y.J.; Kim, W.J.; Chu, I.S. Expression signature of E2F1 and its associated genes predict superficial to invasive progression of bladder tumors. J. Clin. Oncol. 2010, 28, 2660-2667. [CrossRef] [PubMed]

42. Tao, T.; Shi, Y.; Han, D.; Luan, W.; Qian, J.; Zhang, J.; Wang, Y.; You, Y. TPM3, a strong prognosis predictor, is involved in malignant progression through MMP family members and EMT-like activators in gliomas. Tumour Biol. 2014, 35, 9053-9059. [CrossRef] [PubMed] 
43. Choi, H.; Yim, S.; Xu, H.; Jung, S.; Shin, S.; Hu, H.; Jung, C.; Choi, J.; Chung, Y. Tropomyosin3 overexpression and a potential link to epithelial-mesenchymal transition in human hepatocellular carcinoma. BMC Cancer 2010, 10, 122. [CrossRef] [PubMed]

44. WANG, J.; GUAN, J.; LU, Z.; JIN, J.; CAI, Y.; WANG, C.; WANG, F. Clinical and tumor significance of tropomyosin-1 expression levels in renal cell carcinoma. Oncol. Rep. 2015, 33, 1326-1334. [CrossRef] [PubMed]

45. Mitelman, F.; Johansson, B.; Mertens, F. The impact of translocations and gene fusions on cancer causation. Nat. Rev. Cancer 2007, 7, 233-245. [CrossRef] [PubMed]

46. Zhang, Y.; Gong, M.; Yuan, H.; Park, H.; Frierson, H.; Li, H. Chimeric Transcript Generated by cis-Splicing of Adjacent Genes Regulates Prostate Cancer Cell Proliferation. Cancer Discov. 2012, 2, 598-607. [CrossRef] [PubMed]

47. Mariño-Enríquez, A.; Dal Cin, P. ALK as a paradigm of oncogenic promiscuity: different mechanisms of activation and different fusion partners drive tumors of different lineages. Cancer Genet. 2013, 206, 357-373. [CrossRef] [PubMed]

48. de Alava, E.; Kawai, A.; Healey, J.; Fligman, I.; Meyers, P.; Huvos, A.; Gerald, W.; Jhanwar, S.; Argani, P.; Antonescu, C.; et al. EWS-FLI1 fusion transcript structure is an independent determinant of prognosis in Ewing's sarcoma. J Clin. Oncol. 1998, 16, 1248-1255. [CrossRef] [PubMed]

49. Lawrence, B.; Perez-Atayde, A.; Hibbard, M.; Rubin, B.; Dal Cin, P.; Pinkus, J.; Pinkus, G.; Xiao, S.; Yi, E.; Fletcher, C.; et al. TPM3-ALK and TPM4-ALK Oncogenes in Inflammatory Myofibroblastic Tumors. Am. J Pathol. 2000, 157, 377-384. [CrossRef]

50. Stransky, N.; Cerami, E.; Schalm, S.; Kim, J.; Lengauer, C. The landscape of kinase fusions in cancer. Nat. Commun. 2014, 5. [CrossRef] [PubMed]

51. Tate, J.; Bamford, S.; Jubb, H.; Sondka, Z.; Beare, D.; Bindal, N.; Boutselakis, H.; Cole, C.; Creatore, C.; Dawson, E.; et al. COSMIC: the Catalogue Of Somatic Mutations In Cancer. Nucleic Acids Res. 2018, 47, D941-D947. [CrossRef] [PubMed]

52. Takeuchi, K.; Soda, M.; Togashi, Y.; Suzuki, R.; Sakata, S.; Hatano, S.; Asaka, R.; Hamanaka, W.; Ninomiya, H.; Uehara, H.; et al. RET, ROS1 and ALK fusions in lung cancer. Nat. Med. 2012, 18, 378-381. [CrossRef] [PubMed]

53. Wiesner, T.; He, J.; Yelensky, R.; Esteve-Puig, R.; Botton, T.; Yeh, I.; Lipson, D.; Otto, G.; Brennan, K.; Murali, R.; et al. Kinase fusions are frequent in Spitz tumours and spitzoid melanomas. Nat. Commun. 2014, 5. [CrossRef] [PubMed]

54. Eissa, S.; Habib, H.; Ali, E.; Kotb, Y. Evaluation of urinary miRNA-96 as a potential biomarker for bladder cancer diagnosis. Med. Oncol. 2014, 32. [CrossRef] [PubMed]

55. Sin, M.; Mach, K.; Sinha, R.; Wu, F.; Trivedi, D.; Altobelli, E.; Jensen, K.; Sahoo, D.; Lu, Y.; Liao, J. Deep Sequencing of Urinary RNAs for Bladder Cancer Molecular Diagnostics. Clin. Cancer Res. 2017, 23, 3700-3710. [CrossRef] [PubMed]

56. Zhao, M.; Li, M.; Yang, Y.; Guo, Z.; Sun, Y.; Shao, C.; Li, M.; Sun, W.; Gao, Y. A comprehensive analysis and annotation of human normal urinary proteome. Sci. Rep. 2017, 7. [CrossRef] [PubMed]

57. Kalra, H.; Simpson, R.; Ji, H.; Aikawa, E.; Altevogt, P.; Askenase, P.; Bond, V.; Borràs, F.; Breakefield, X.; Budnik, V.; et al. Vesiclepedia: A Compendium for Extracellular Vesicles with Continuous Community Annotation. PLoS Biol. 2012, 10, e1001450. [CrossRef] [PubMed]

58. Dube, S.; Yalamanchili, S.; Lachant, J.; Abbott, L.; Benz, P.; Mitschow, C.; Dube, D.; Poiesz, B. Expression of Tropomyosin 1 Gene Isoforms in Human Breast Cancer Cell Lines. Int. J. Breast Cancer 2015, 2015, 1-11. [CrossRef] [PubMed]

59. Dube, S.; Thomas, A.; Abbott, L.; Benz, P.; Mitschow, C.; Dube, D.; Poiesz, B. Expression of tropomyosin 2 gene isoforms in human breast cancer cell lines. Oncol. Rep. 2016, 35, 3143-3150. [CrossRef] [PubMed]

60. Yang, W.; Wang, X.; Zheng, W.; Li, K.; Liu, H.; Sun, Y. Genetic and epigenetic alterations are involved in the regulation of TPM1 in cholangiocarcinoma. Int. J. Oncol. 2012, 42, 690-698. [CrossRef] [PubMed]

61. Thorsen, K.; Sørensen, K.; Brems-Eskildsen, A.; Modin, C.; Gaustadnes, M.; Hein, A.; Kruhøffer, M.; Laurberg, S.; Borre, M.; Wang, K.; et al. Alternative Splicing in Colon, Bladder, and Prostate Cancer Identified by Exon Array Analysis. Mol. Cell. Proteom. 2008, 7, 1214-1224. [CrossRef] [PubMed] 
62. Lin, J.; Geng, X.; Bhattacharya, S.; Yu, J.; Reiter, R.; Sastri, B.; Glazier, K.; Mirza, Z.; Wang, K.; Amenta, P.; et al. Isolation and sequencing of a novel tropomyosin isoform preferentially associated with colon cancer. Gastroenterology 2002, 123, 152-162. [CrossRef] [PubMed]

63. Zare, M.; Jazii, F.; Soheili, Z.; Moghanibashi, M. Downregulation of tropomyosin-1 in squamous cell carcinoma of esophagus, the role of Ras signaling and methylation. Mol. Carcinog. 2011, 51, 796-806. [CrossRef] [PubMed]

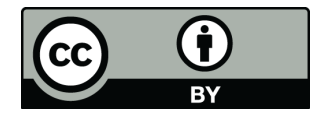

(C) 2019 by the authors. Licensee MDPI, Basel, Switzerland. This article is an open access article distributed under the terms and conditions of the Creative Commons Attribution (CC BY) license (http://creativecommons.org/licenses/by/4.0/). 